\title{
Reliability Calculation for a Multilayered Coating Based on a Model with Independently (Sequentially) Degrading Layers
}

\author{
Aleksei Osinnii1 ${ }^{1, *}$, Anatoli Chigarev², Jury Bublikov${ }^{3}$, Mikhail Mosyanov $^{1}$, Anton Kekalo ${ }^{1}$ \\ ${ }^{1}$ Moscow State Technological University "STANKIN", RU-127055, Moscow, Russia \\ ${ }^{2}$ Belarusian State University, BL-220030, Minsk, Belarus. \\ ${ }^{3}$ IDTI RAS, Moscow, Russia.
}

\begin{abstract}
The paper proposes methods to predict the reliability of a multilayered coating based on a model with independently (sequentially) degrading layers. For the mathematical description of the process of crack penetration into the depth of a layered solid body from the free surface with certain roughness, the propagation of a crack tip into a layer adjacent to the free boundary of the coating is considered. This stochastic process is described through the specification of all multipoint probability distributions (densities), and it represents a Markov process. A mathematical model, described by equations of the parabolic type, is proposed to describe the above-mentioned process. Based on the above model, graphs are constructed to describe the change in the time of the crack propagation through a layer depending on the surface roughness and the ultimate strength (ductility) of the coating. The crack growth rate will be in the range from $10^{-6} \mathrm{~mm} / \mathrm{s}$ (when the surface roughness is low) to $10^{-4} \mathrm{~mm} / \mathrm{s}$ (when the surface roughness is high).
\end{abstract}

\section{Introduction}

Brittle fracture occurring as a result of the active cracking is a significant factor in the wear and failure of metal-cutting tools [1]. In most cases, modern metalcutting tools are manufactured with wear- resistant coatings $[2,3]$. The challenge of predicting the reliability of the coatings of various compositions and architecture and, in particular, of modeling the coating resistance to brittle fracture is crucial and urgent. The brittle fracture of coatings can be modeled using various approaches. The traditional methods treat the crack growth as a deterministic process. In this case, a finite element model (FEM) is being widely used [4-12]. In particular, the influence of such factors as specific features of the coating material, the number of loading cycles, and the surface microgeometry was studied [4,5]. Several papers developed models to simulate the coating fracture during the scratch testing [6-9]. The effect of the substrate roughness on the fracture pattern on the coating was investigated [10]. The influence of defects in a coating on its fracture pattern was considered [11-18]. To predict the crack resistance of a coating, a shear-lag model was used which made it possible to take into account the through thickness inhomogeneity of the coating [19]. The discrete element method (DEM) was also used [20]. To predict the brittle fracture resistance of the coatings, the Bower/Fleck's and Hamilton's equations were applied [21]. The fracture toughness model was also considered, in which crack tip opening displacement was used to predict the crack propagation velocity [22]. In
[23,24], linear elastic fracture mechanics (LEFM) was used to model the process of cracking in a coating depending on the substrate microgeometry, the properties of the coating material, and the applied loading.

However, in fact, the process of crack growth is a stochastic process, during which only the average crack growth rate can be determined, with the fallibility of $n(t)$, which average value is $\langle\mathrm{n}(\mathrm{t})\rangle=0$. To implement the above approach, the probabilistic methods are used to take into account the stochastic nature of both the process of the coating formation and the process of the coating fracture [25-31]. It should also be considered that most of the modern coatings have a multilayered architecture, with alternating layers with different mechanical properties [32-37]. The application of the modern technologies and methods of the coating deposition [38-47] has significant influence on the properties of the coatings, which should be taken into account when developing the modern methods of modeling. The specific features of cracking and brittle fracture of the coatings of various compositions and architecture were considered in several papers [48-7]. The objective of this study is to develop methods to run the reliability calculation of a multilayered coating based on a model with independently (sequentially) degrading layers. 


\section{Model of crack propagation in a coating layer}

A real surface is characterized by a certain level of roughness, that is, a set of irregularities occurring with relatively small steps along the base length. The roughness refers to the microgeometry of solid objects and determines their most important performance properties. Surface microdepressions are stress concentrators and potential areas for the start of crack formation. A crack can develop on the coating surface by forming a grid of surface cracks (cracking) or growing deep into the coating material. A crack directed deep into the coating material consists of two surfaces intersecting along the crack front line. During the process of its development, a crack can bend, branch, and behave in a complex manner; however, in general, the fracture mechanics considers the propagation of cracks in a plane, along a rectilinear path. Thus, in order to describe mathematically the process of crack propagation into the depth of a layered solid object from the free surface with a certain roughness, the consideration will be focused on the motion of a crack tip (a point at the crack front) in a layer, adjacent to the free interface from an initial microcrack, a depression on the surface. Let one of the coordinate axes be directed along a rectilinear inplane trajectory, while the other axis is directed along the roughness midline (Fig. 1).

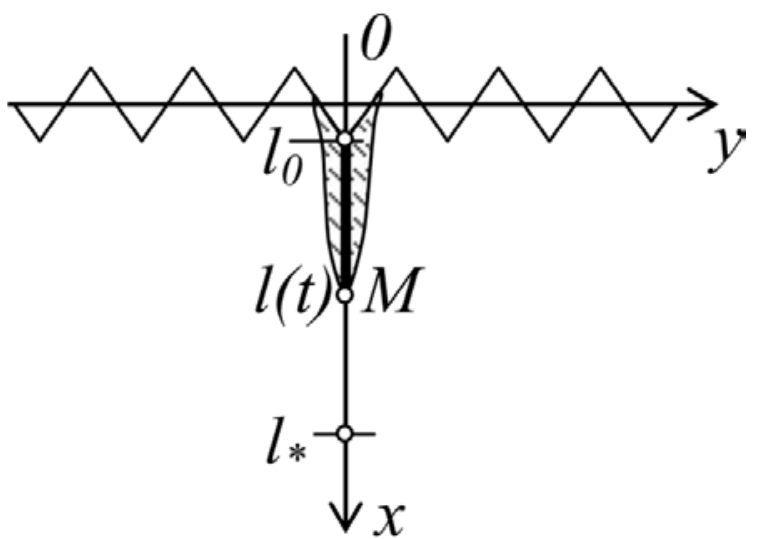

Fig. 1. Coordinate system and a model of crack propagation deep into the layered coating structure.

Figure 3 depicts $l_{0}$ as the depth of the depression relative to the roughness midline, which can be considered as the initial point of crack propagation, from which the crack begins to grow deep into the coating material, along the axis $\mathrm{x}, l_{*}$ is the thickness of the upper layer of the coating, $l=l(t)$ is the length of the crack at the time point $t$, a random function. During the process of crack growth, the function $l(t)$ can either grow or remain constant at some time point, and therefore, a model of random walk along a straight line is chosen. As is known, a random process is described by specifying all multipoint probability distributions (densities) or moments. For example, a two-point distribution is known to be written as:

$$
P\left(l_{1}, t_{1}, l_{2}, t_{2}\right)=\Pi\left(l_{2}, t_{2} \mid l_{1}, t_{1}\right) P\left(l_{1}, t_{1}\right)
$$

Where $\Pi\left(l_{2}, t_{2} \mid l_{1}, t_{1}\right)$ describes the probability that at the time point $t_{2}$, the crack has the length $l\left(t_{2}\right)=l_{2}$ provided that at the time point $t_{1}$, it has the length $l\left(t_{1}\right)=l_{1}$.

Then, if assumed that the information about the crack length $l_{21}$ at the time point $t_{2}$ depends only on the information about the crack length $l_{1}$ at the time point $t_{1}$, then all multipoint probability distributions are described in terms of the conditional (transition probabilities, probability densities) $\Pi\left(l_{2}, t_{2} \mid l_{1}, t_{1}\right)$. This is a Markov process, and it is possible to develop a mathematical model for it described by parabolic equations. In general, such equations cannot be solved analytically, but a solution can be reached using the finite difference method (FDM) (1D) or finite element method (FEM) (2D, 3D). The solution depends on the final and boundary conditions, thickness of layers and their physical and mechanical properties (elastic modulus, fracture strength, and stress intensity factors). This means it is necessary to specify $A(l), B(l)$ in the equation (1). $A(l)$ describes the forward motion of the crack and depends on the values listed above. $B(l)$ describes a random error in the estimation of the crack propagation velocity $d l / d t$ due to its random behaviour. It is assumed that the crack propagation will be quite smooth, without any sudden accelerations and stops. Based on the above, let $B(l)=\frac{N_{0}}{2}$ - const. A linear approximation is assumed for $A(l)$, with thin layers, so that

$$
A(l)=A\left(l_{0}+\Delta l\right) \approx A\left(l_{0}\right)+A^{\prime}\left(l_{0}\right) \Delta l
$$

where $\Delta l=l-l_{0}, A^{\prime}=\frac{d A}{d l}$

Then the linear model of crack development can be written in the following form:

$$
\frac{d l}{d t}=\left(A_{0}+A_{1} l\right)+\frac{N_{0}}{2} \delta(t)
$$

It can also be assumed that $\Pi\left(l_{2}, t_{2} \mid l_{1}, t_{1}\right)$ depends not on the time points $t_{1}, t_{2}$, but on their difference $t_{2}-t_{1}=\tau$, i.e. there is a steady state of the crack development process. This assumption is quite admissible because of the progressive crack growth mechanism, for example, under cyclic loads, depending not on the specific exposure time points $t_{1}, t_{2}$, but on the exposure duration:

$$
\begin{aligned}
& \Pi\left(l_{2}, t_{2} \mid l_{1}, t_{1}\right)=\Pi_{t}\left(l_{2} \mid l_{1}\right)= \\
& \Pi\left(l_{2} \mid l_{1}, t_{2}-t_{1}\right)=\Pi\left(l_{2} \mid l_{1}, \tau\right)
\end{aligned}
$$

Then for $\Pi_{\tau}\left(l_{2} \mid l_{1}\right)$, two types of equations will be obtained:

the direct equation:

$$
\frac{\partial \Pi_{\tau}}{\partial \tau}=\frac{\partial}{\partial l_{2}}\left(l_{2} \Pi_{\tau}\right)+\frac{\partial^{2} \Pi_{\tau}}{\partial l_{2}^{2}}
$$

the inverse equation:

$$
\frac{\partial \Pi_{\tau}}{\partial \tau}=-l_{1} \frac{\partial \Pi_{\tau}}{\partial l_{1}}+\frac{\partial^{2} \Pi_{\tau}}{\partial l_{1}^{2}}
$$


The solution of $\Pi_{\tau}\left(l_{2} \mid l_{1}\right)$ describes the steady-state Gaussian Markov process:

$$
\Pi_{\tau}\left(l_{2} \mid l_{1}\right)=\frac{1}{\sqrt{2 \Pi\left(1-l^{-2 \tau}\right)}} \exp \left\{-\frac{\left(l_{2}-l_{1} e^{-2 \tau}\right)^{2}}{2\left(1-e^{-2 \tau}\right)}\right\}
$$

For $P_{1}(l)$ :

$$
P_{1}\left(l_{1}\right)=\frac{1}{\sqrt{2 \Pi}} e^{-1 / 2 l_{1}^{2}}
$$

The condition of normalization for $\Pi_{\tau}\left(l_{2} \mid l_{1}\right)$ should be satisfied:

$$
\int \Pi_{\tau}\left(l_{2} \mid l_{1}\right) d l_{2}=1
$$

The probability that the crack length $l(t)$ reaches the value of $l=l_{1}$ is calculated by the formula:

$$
P_{1}\left(l_{1}\right)=\int \Pi_{\tau}\left(l_{2} \mid l_{1}\right) P_{1}\left(l_{2}\right) d l_{2}
$$

As is known, the Gaussian approximation for a random variable is determined by two parameters: the mean (expected value) and the dispersion.

$$
m_{l}(l)=\langle l(t)\rangle, D_{l}(t)=\left\langle(l(t)-\langle l(t)\rangle)^{2}\right\rangle
$$

And it can generally be written as

$$
P(l, t)=\frac{1}{\sqrt{2 \Pi D_{l}(t)}} \exp \left\{-\frac{\left(l(t)-m_{l}(t)\right)^{2}}{2 D_{l}(t)}\right\}
$$

Here, the equations for $m_{l}(t)$ and $D_{l}(t)$ are found from the equation (3) by the method of averaging:

$$
\begin{gathered}
\frac{d m_{l}(t)}{d t}=\left(A_{0}+A_{1}\right) m_{l}(t) \\
\frac{d D_{l}(t)}{d t}=2 D_{l}+B m_{l}(t)
\end{gathered}
$$

The solutions of (13) and (14) are expressed as

$$
\begin{gathered}
m_{l}(t)=m_{l}(0) \exp \left[\left(A_{0}+A_{1}\right) t\right] \\
D_{l}(t)=\frac{N_{0}}{2}
\end{gathered}
$$

Let us take a generalize model of the crack growth in the form:

$$
\frac{d l}{d t}=-\gamma l+\frac{N}{4 l}+n(t)
$$

Where $N=\omega l_{*} \sqrt{\frac{\left(1-l_{0} / l_{*}\right) G^{2}}{\sigma_{0} E}}, \gamma=\omega \frac{(1-v) E}{\left(1-l_{0} / l_{*}\right) G}$

For the problem of the crack growth, of the main interest is the time during which a crack cuts through a layer. It is clear that on a set of identical layers, the time period $\mathrm{T}$ during which a crack cuts through a layer is a continuous random variable which can be described using probabilistic moments, dispersion, etc.

Let us present the mean time $T_{1}=\langle T\rangle=T\left(0, \frac{l_{0}}{\sigma}, \frac{l_{*}}{\sigma}\right)$ in a form convenient for numerical calculations:

$$
T_{1}\left(0, \frac{l_{0}}{\sigma}, \frac{l_{*}}{\sigma}\right)=\frac{1}{2 \gamma} \sum_{K=1}^{\infty} \frac{1}{K ! K}\left[\left(\frac{l_{*}^{2}}{2 \sigma^{2}}\right)^{K}-\left(\frac{l_{0}^{2}}{2 \sigma^{2}}\right)^{K}\right]
$$

An error in the calculation of $T_{1}$, the average operating time of a layer, is determined by the dispersion $D$, which can be written in a form convenient for calculations as follows:

$$
\begin{gathered}
D\left(0, \frac{l_{0}}{\sigma}, \frac{l_{*}}{\sigma}\right)=\frac{1}{2 \gamma} \sum_{n=1}^{\infty} \frac{1}{2 n^{2}} \sum_{K=0}^{2 n-1} \frac{(-1)^{K+1}}{K !} \\
{\left[l^{2} / 2 \sigma^{2}\left(\frac{l_{*}^{2}}{2 \sigma^{2}}\right)^{K}-l_{0}^{2} / 2 \sigma^{2}\left(\frac{l_{0}^{2}}{2 \sigma^{2}}\right)^{K}\right]}
\end{gathered}
$$

If no roughness is taken into account, i.e. $l_{0}=0$, then (18) is simplified to the following form:

$$
\begin{gathered}
D\left(0, \frac{l_{0}}{\sigma}, \frac{l_{*}}{\sigma}\right)=\frac{1}{2 \gamma^{2}} \sum_{n=1}^{\infty} \frac{1}{2 n^{2}} \\
\left\{1-l_{*}^{l_{*}^{2} / 2 \sigma^{2}}\left[1+\sum_{K=1}^{2 n-1} \frac{(-1)^{K}}{K !}\left(\frac{l_{*}^{2}}{2 \sigma^{2}}\right)^{K}\right]\right\}
\end{gathered}
$$

The model (16) considers two terms that behave differently and take into account softening and resistance to crack growth. It is known from the fracture mechanics that with an increase in the crack length, the forces required for its growth decrease, which is taken into account by the second term in the formula (16). The coefficient $N_{0}$ depends on the physical and mechanical properties (Yung's modulus, yield strength), while the coefficient $\gamma$ takes into account the opposite tendency in fracture. Figure 2 depicts in the dimensionless axes the curves describing the relationships between $\gamma T_{1}$ and $l_{*} / \sigma$ at the given values of the roughness and layer thickness, built based on the formula (10).

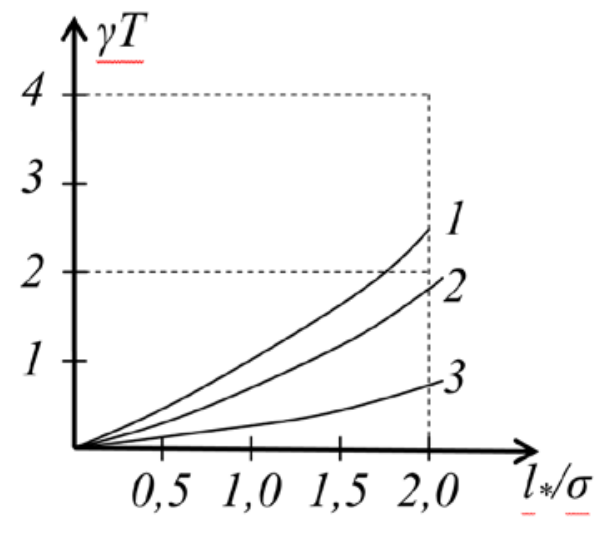

Fig. 2. Curves describing the relationships between $\gamma T$ and $l_{*} / \sigma$ at the given roughness and layer thickness.

1. $l_{0} / l_{*}=0, N=10^{-6} \mathrm{~mm} / \mathrm{sec}$ is low roughness

2. $l_{0} / l_{*}=\frac{1}{4}, N=10^{-5} \mathrm{~mm} / \mathrm{sec}$ is mean roughness

3. $l_{0} / l_{*}=\frac{3}{4}, N=10^{-4} \mathrm{~mm} / \mathrm{sec}$ is high roughness

Figure 3 exhibits the curves estimating an error (dispersion), also built based on the formula (10). 


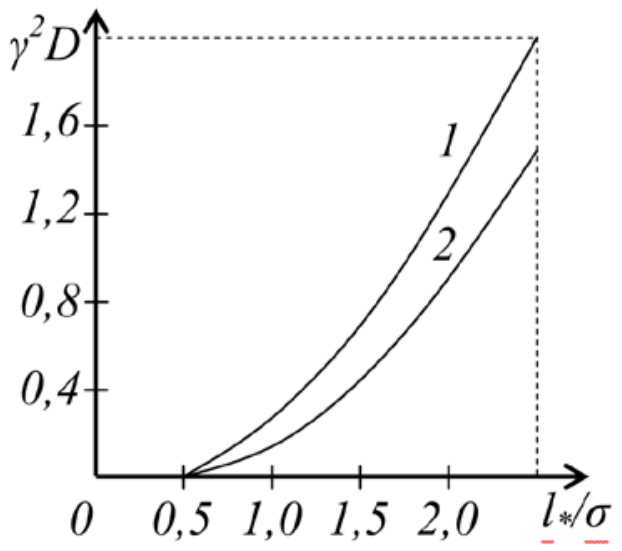

Fig. 3. Curves for estimating an error (dispersion) $\gamma^{2} D$ on $l_{*} / \sigma$.

1. Under the conditions:

$$
l_{0} / l_{*}=0, N=10^{-6} \mathrm{~mm} / \mathrm{s}, \quad \gamma=10^{-5} / \mathrm{s}
$$

2. Under the conditions:

$$
l_{0} / l_{*}=\frac{3}{4}, N=10^{-5} \mathrm{~mm} / \mathrm{s}, \quad \gamma=10^{-4} / \mathrm{s}
$$

The connection between $N_{0}$ and $\gamma$ is described based on the formula of $\sigma^{2}=\frac{N_{0}}{4 \gamma}$.

\section{Conclusions}

The paper proposes the methods to predict the reliability of a multilayered coating based on a model with independently (sequentially) degrading layers. A crack propagates along the $\mathrm{x}$-axis depending on the time $\mathrm{t}$ or the number of loading cycles and is generally a random function. For the mathematical description of the process of crack penetration into the depth of a layered solid body from the free surface with certain roughness, the propagation of a crack tip into a layer adjacent to the free boundary of the coating starting from an irregularity (depression) on the surface is considered. This stochastic process is described through the specification of all multipoint probability distributions (densities), and it represents a Markov process. The mathematical model, described by equations of the parabolic type, is proposed to describe the above-mentioned process. Based on the above model, the graphs are constructed to describe the change in the time of the crack propagation through a layer depending on the surface roughness and the ultimate strength (ductility) of the coating. The crack growth rate $\mathrm{T}$ will be in the range from $10^{-6} \mathrm{~mm} / \mathrm{s}$ (when the surface roughness is low) to $10^{-4} \mathrm{~mm} / \mathrm{s}$ (when the surface roughness is high). The dispersion $\mathrm{D}$ also increases with an increase in roughness.

\section{Acknowledgments}

This research was funded by Ministry of Science and Higher Education of the Russian Federation, Grant No. 0707-2020-0025. This work was carried out using equipment provided by the Center of Collective Use of MSUT "STANKIN".

\section{References}

1. V. Astakhov, J. Davim, Tools (Geometry and Material) and Tool Wear (Machining. Springer, 2008)

2. A.A. Vereschaka, S.N. Grigoriev, N.N. Sitnikov, A.D. Batako, Wear, 390-391, 209, (2017)

3. A. Vereschaka, V. Tabakov, S. Grigoriev, N. Sitnikov, G. Oganyan, N. Andreev, F. Milovich, Wear, 420-421, 17-37, (2019)

4. P. Bansal, P.H. Shipway, S.B. Leen, Surf.Coat. Technol., 200(18-19), 5318, (2006)

5. M. Bäker, Comput. Mater, Sci., 64, 79, (2012)

6. Z. Xia, W.A. Curtin, B.W. Sheldon, Acta Mater, 52, 3507, (2004)

7. J.H. Lee, Y.F. Gao, K.E. Johanns, G.M. Pharr, Acta Mater, 60, 5448, (2012)

8. H.C. Hyun, F. Rickhey, J.H. Lee, M. Kim, H. Lee, Eng. Fract. Mech., 134, 304, 2015)

9. K. Holmberg, A. Laukkanen, H. Ronkainen, K. TribolInt, 38, 1035, (2005)

10. T.L. Anderson, Fracture Mechanics: Fundamentals and Applications (CRC Press, Boca Raton, 1994)

11. K. Holmberg, A. Laukkanen, E. Turunen, T. Laitinen, Surf.Coat. Technol., 247, 1-13, (2014)

12. A.L. Mohd Tobi, P.H. Shipway, S.B. Leen, Tribol Int, 58, 29, (2013)

13. E. Harry, M. Ignat, Y. Pauleau, A. Rouzaud, P. Juliet. Surf. Coat. Technol., 125, 185, (2000)

14. L. Aihua, D. Jianxin, C. Haibing, C. Yangyang, Z. Jun. Int. J. Refract. Hard. Met., 31, 82, (2012)

15. A. Vereschaka, V. Tabakov, S. Grigoriev, N. Sitnikov, F. Milovich, N. Andreev, J. Bublikov, Wear, 438, 203069, (2019)

16. A. Vereschaka, S. Grigoriev, N. Sitnikov, F. Milovich, A. Aksenenko, N. Andreev, Int. J. Adv. Manuf. Technol., 102(9-12), 2953, (2019)

17. V. Alexey, Key. Eng. Mater., 581, 62, (2014)

18. M. Antonov, I. Hussainova, F. Sergejev, P. Kulu, A. Gregor, Wear, 267, 898, (2009)

19. K. Wang, F. Zhang, R.K. Bordia, Materials, 11(4), 497, (2018)

20. N. Ferguen, Y. Mebdoua-Lahmar, H. Lahmar, W. Leclerc, M. Guessasma. Surf. Coat. Technol., 371, 287, (2019)

21. M. Białas, Surf. Coat. Technol., 202(24), 6002, (2008)

22. Y. Gu, K. Chen, R. Liu, M.X. Yao, R. Collier, Surf. Coat. Technol., 309, 536, (2017)

23. X.-F. Wu, R.A. Jenson, Int. J. Eng. Sci., 49(3), 279, (2011)

24. X.-F. Wu, R.A. Jenson, Y. Zhao, Mech. Mater., 69(1), 195, (2014)

25. M. Grujicic, S.G. Lai, J. Mater. Sci., 36(12), 2937, (2001) 
26. C.K. Birdsall, PIC-MCC., IEEE Trans. Plasma Sci., 19(2), 65, (1991)

27. D.T.K. Kwok, C. Cornet, IEEE Trans. Plasma Sci., 34, 2434, (2006)

28. E. Bultinck, A. Bogaerts, New J. Phys., 11, 103010, (2009)

29. M. Siemers, A. Pflug, T. Melzig, K. Gehrke, A. Weimar, B. Szyszka, Surf. Coat. Technol., 241, 50, (2014)

30. H. Cansizoglu, M. Yurukcu, M.F. Cansizoglu, T. Karabacak, Thin Solid Films, 583(1), 122, (2015)

31. S. Kumar, W.A. Curtin, Materials Today, 10(9), 34, (2007)

32. G. Skordaris, K.-D. Bouzakis, P. Charalampous, Surf. Coat. Technol., 265, 53, (2015)

33. B.D. Beake, L. Ning, Ch. Gey, S.C. Veldhuis, A. Komarov, A. Weaver, M. Khanna, G.S. FoxRabinovich, Surf. Coat. Technol., 279, 118, (2015)

34. L. Ning, S.C. Veldhuis, K. Yamamoto, Int. J. Mach. Tools Manuf., 48, 656, (2008)

35. A. Vereschaka, V. Tabakov, S. Grigoriev, A. Aksenenko, N. Sitnikov, G. Oganyan, A. Seleznev, S. Shevchenko, Surf. Coat. Technol., 357, 218, 2019)

36. A. Vereschaka, V. Tabakov, S. Grigoriev, N. Sitnikov, N. Andreev, F. Milovich, Wear, 416, 772, (2018)

37. B.D. Beake, G.S. Fox-Rabinovich, Surf. Coat. Technol., 255, 102, (2014)

38. S.N. Grigoriev, M.A. Volosova, A.A. Vereschaka, N.N. Sitnikov, F. Milovich, J.I. Bublikov, S.V. Fyodorov, A.E. Seleznev, Ceram. Int., 46(11), 1824, (2020)

39. W. Kalss, A. Reiter, V. Derflinger, C. Gey, J.L. Endrino, Int. J. Refractory Met. Hard Mater., 24(5), 399, (2006)

40. K. Bobzin, CIRP J. Manuf. Sci. Technol., 18, 1, (2017)

41. M.A. Volosova, S.N. Grigor'ev, V.V. Kuzin, Refract. Ind. Ceram., 55, 565, (2015)

42. S. Grigoriev, Y. Melnik, A. Metel, Surf. Coat. Technol., 156(1-3), 44, (2002)

43. M.A. Volosova, S.N. Grigor'ev, V.V. Kuzin, Refract. Ind. Ceram., 55, 487, (2015)

44. V.V. Kuzin, S.N. Grigor'ev, M.A. Volosova, Refract. Ind. Ceram., 54, 376, (2014)

45. V.V. Kuzin, S.N. Grigoriev, M.Yu. Fedorov, J. Frict Wear, 36(1), 40, (2015)

46. A.S. Metel, S.N. Grigoriev, Yu.A. Melnik, V.P. Bolbukov, Instrum. Exp. Tech., 55(1), 122, (2012)

47. M.A. Volosova, S.N. Grigor'ev, V.V. Kuzin, Refract Ind Ceram, 56, 91, (2015)

48. A.S. Vereschaka, S.N. Grigoriev, V.P. Tabakov, E.S. Sotova, A.A. Vereschaka, M.Y. Kulikov, Key Eng. Mater., 581, 68, (2014)
49. S.N. Grigoriev, O.V. Sobol, V.M. Beresnev, I.V. Serdyuk, A.D. Pogrebnyak, D.A. Kolesnikov, U.S. Nemchenko, J. Frict. Wear, 35(5), 359, (2014)

50. A. Metel, V. Bolbukov, M. Volosova, S. Grigoriev, Y. Melnik, Surf. Coat. Technol., 225, 34, (2013)

51. A.S. Vereschaka, S.N. Grigoriev, E.S. Sotova, A.A. Vereschaka, Adv Mat Res, 712-715, 391, (2013)

52. A.A. Vereschaka, A.S. Vereschaka, S.N. Grigoriev, A.K. Kirillov, O. Khaustova, Procedia CIRP, 7, 311, (2013)

53. A.A. Vereschaka, S.N. Grigoriev, N.N. Sitnikov, G.V. Oganyan, A. Batako, Surf.Coat. Technol., 332, 198, (2017)

54. A. Vereschaka, V. Tabakov, S. Grigoriev, N. Sitnikov, F. Milovich, N. Andreev, C. Sotova, N. Kutina, Surf. Coat. Technol., 385, 125402, (2020)

55. A. Vereschaka, A. Aksenenko, N. Sitnikov, M. Migranov, S. Shevchenko, C. Sotova, A. Batako, N. Andreev, Tribol. Int. 128, 313 (2018)

56. V. Alexey, Adv Mat Res, 712-715, 347, (2013)

57. J. Gradišek, I. Grabec, S. Siegert, R. Friedrich, Mech Syst Signal Process, 16(5), 831, (2002)

58. A. Vereschaka, M. Volosova, A. Chigarev, N. Sitnikov, A. Ashmarin, C. Sotova, J. Bublikov, D. Lytkin, Coatings, 10(1), 63, (2020)

59. S. Grigoriev, A. Vereschaka, F. Milovich, V. Tabakov, N. Sitnikov, N. Andreev, T. Sviridova, J. Bublikov, Surf. Coat. Technol., 401, 126258, (2020)

60. A.A. Vereshchaka, A.S. Vereshchaka, O. Mgaloblishvili, M.N. Morgan, A.D. Batako, Int. J. Adv. Manuf. Tech., 72(1-4), 303, (2014)

61. M. Volosova, S. Grigoriev, A.Metel, A. Shein, Coatings, 8, 287, (2018)

62. M.A. Volosova, S.N. Grigor'ev, V.V. Kuzin, Refract. Ind. Ceram., 56, 197, (2015)

63. O.V. Sobol', A.A. Andreev, S.N. Grigoriev, V.A. Stolbovoy, Probl. At. Sci. Technol., 4, 174, (2011)

64. V.V. Kuzin, S.N. Grigoriev, M.A. Volosova, J. Frict. Wear, 35, 505, (2014)

65. M.A. Volosova, S.N. Grigoriev, E.A. Ostrikov, Mech. Ind., 17, 720, (2016)

66. Moës, N., Dolbow, J., Belytschko, T. Int J Numer Methods Eng., 46(1), 131, (1999)

67. Kumar, K.S., Van Swygenhoven, H., Suresh, S. Acta Materialia, 51(19), 5743, (2003)

68. Moës, N., Belytschko, T. Engineering Fracture Mechanics, 69(7), 813, (2002)

69. Rabczuk, T., Belytschko, T. Int J Numer Methods Eng., 61(13), 2316, (2004)

70. Miehe, C., Welschinger, F., Hofacker, M. Int J Numer Methods Eng., 83(10), 1273, (2010) 